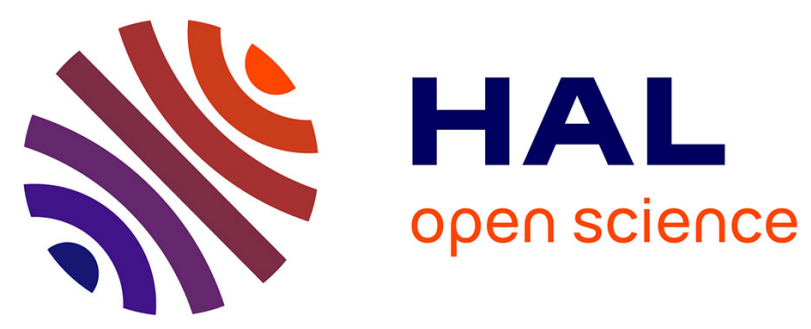

\title{
Theoretical analysis of the kinetics of precipitation of lizardite and magnesite from olivine alteration
}

\author{
B. Fritz, A. Clément, G. Montes-Hernandez, C. Noguera
}

\section{To cite this version:}

B. Fritz, A. Clément, G. Montes-Hernandez, C. Noguera. Theoretical analysis of the kinetics of precipitation of lizardite and magnesite from olivine alteration. Chemical Geology, 2018, 497, pp.18 26. 10.1016/j.chemgeo.2018.08.011. hal-01912212

\section{HAL Id: hal-01912212 \\ https://hal.sorbonne-universite.fr/hal-01912212}

Submitted on 12 Nov 2018

HAL is a multi-disciplinary open access archive for the deposit and dissemination of scientific research documents, whether they are published or not. The documents may come from teaching and research institutions in France or abroad, or from public or private research centers.
L'archive ouverte pluridisciplinaire $\mathbf{H A L}$, est destinée au dépôt et à la diffusion de documents scientifiques de niveau recherche, publiés ou non, émanant des établissements d'enseignement et de recherche français ou étrangers, des laboratoires publics ou privés. 


\title{
Theoretical analysis of the kinetics of precipitation of lizardite and magnesite from olivine alteration.
}

\author{
B. Fritz, ${ }^{1}$ A. Clément, ${ }^{1}$ G. Montes-Hernandez, ${ }^{2}$ and C. Noguera ${ }^{3}$ \\ ${ }^{1}$ Université de Strasbourg/EOST,CNRS, Laboratoire d'Hydrologie et de Géochimie de Strasbourg, \\ 1 rue Blessig, F-67084 Strasbourg Cedex, France \\ ${ }^{2}$ CNRS and University Joseph Fourier - Grenoble 1, Institute of Earth Sciences (ISTerre), \\ OSUG/INSU, BP 53, 38041 Grenoble Cedex 9, France \\ ${ }^{3}$ CNRS-Sorbonne Universités, UPMC Univ. Paris 06, UMR 7588, INSP, F-75005 Paris, France
}

(Dated: October 31, 2018)

\begin{abstract}
The present theoretical study analyzes the kinetic characteristics of precipitation of magnesite and lizardite as a result of hydrothermal alteration of olivine under high carbonate alkalinity. It makes use of a simulation strategy in which, both the chemical evolution of the aqueous solution and the solid phases are considered. The simulation is performed with the help of the NANOKIN code. It includes a full treatment of speciation processes in the aqueous solution, a rate equation for the dissolution of olivine, and a full account of nucleation and growth processes during the formation of secondary particles. The comparison between experimental (Lafay et al., 2014) and simulation results puts strong constraints on the simulation parameters, in particular those related to the nucleation and growth of the particles. Modeling points to an incongruent olivine dissolution and reveals a transitory precipitation of $\mathrm{SiO}_{2}$, not detected experimentally, showing that the fate of $\mathrm{Si}$ is more complex than a mere incorporation in lizardite. It highlights how lizardite, magnesite and $\mathrm{SiO}_{2}$ compete for the incorporation of silicon and magnesium released by the olivine dissolution.
\end{abstract}

Keywords: hydrothermal alteration, $\mathrm{CO}_{2}$, nucleation and growth, computer simulation, NANOKIN code, nanoparticles, olivine, magnesite, lizardite

PACS numbers:

\section{INTRODUCTION}

In the context of the increasing global warming of the Earth atmosphere, thought to be essentially due to anthropogenic $\mathrm{CO}_{2}$ emissions, artificial weathering of magnesium bearing silicates, widespread in the Earth crust, has been proposed as a promising solution for geological storage of $\mathrm{CO}_{2}$. During such an industrial process, gaseous $\mathrm{CO}_{2}$ would be dissolved into an aqueous solution subsequently injected into the geological reservoir. The drop in $\mathrm{pH}$ in the solution due to $\mathrm{CO}_{2}$ would induce the silicate dissolution before its carbonation. Understanding the reaction mechanisms, the kinetics and the role of pressure, temperature and $\mathrm{pH}$ has stimulated numerous experimental studies of the serpentinization or carbonation of various silicates (Luce et al., 1972; Chen and Brantley, 2000; Oelkers, 2001; James et al., 2003; Giammar et al., 2005; Bearat et al., 2006; Hänchen et al., 2006; Prigiobbe et al., 2009; Andreani et al. 2009; Garcia et al. 2010; King et al., 2010; Daval et al., 2011; Malvoisin et al., 2012; Gadikota et al., 2014).

These studies mainly focused on the determination of kinetic rate laws of dissolution as those control the availability of chemical elements from the altered minerals. However experimental approaches generally show coexisting dissolution and precipitation, which opens the question of feed-back effects and complex coupling between secondary mineral precipitation and the dissolution process that initiates the whole alteration process. This was, in particular, the case for Lafay et al. (2014), who recently studied the simultaneous precipitation of lizardite and magnesite from hydrothermal alteration of olivine under high-carbonate alkalinity in the lab. This work raised interesting questions on the competitive incorporation of magnesium and silicon released by the dissolution of olivine, into the two secondary mineral phases.

In the present work, we complement these lab experiments by a simulation strategy allowing a better understanding of these complex processes which coexist in natural hydrothermal systems. Our kinetic modeling treats on an equal footing dissolution and precipitation processes. It makes use of the NANOKIN home made simulation code (Noguera et al., 2006a,b; Fritz et al., 2009), which allows an account of ion speciation in the aqueous solution, dissolution, nucleation and growth processes. It has been recently applied to decipher the mechanism of calcite formation by hydrothermal carbonation of portlandite (Fritz et al., 2013), as well as to analyze the characteristics of amorphous silica nanoparticles precipitation under various thermodynamic conditions (Noguera et al., 2015).

The paper is organized as follows. Section II provides information on the synthesis route and a thorough interpretation of thermogravimetric analysis results (TGA). The numerical method is presented in Section III and the choice of the parameter values is discussed. The main results on the alteration of olivine are presented in Section IV. In the last section (Section V), the incongruent olivine dissolution and the existence of a transitory $\mathrm{SiO}_{2}$ secondary phase are discussed. A preliminary attempt to 
take into account the Fe content of the San Carlos olivine is described. Finally, we analyze on which basis relies the competition between lizardite, magnesite and $\mathrm{SiO}_{2}$ for the incorporation of silicon and magnesium released by the olivine dissolution. Section VI is a conclusion.

\section{EXPERIMENTAL RESULTS AND THEIR INTERPRETATION}

In this section, we first recall the experimental conditions under which simultaneous precipitation of magnesite and lizardite has been obtained and characterized (Lafay et al., 2014). Then we propose a re-interpretation of the TGA data, allowing to determine the time evolution of the absolute amounts of each solid phase.

\section{A. Synthesis and characterization}

Two alkaline solutions have been prepared (Lafay et al., 2014). The first one (S1), recovered from magnesite synthesis (Montes-Hernandez et al., 2012a,b) had a pH of 8.9 (measured at $20^{\circ} \mathrm{C}$ ), a high concentration of total carbon $(\mathrm{TC}=1 \mathrm{M})$ and low concentration of $\mathrm{Mg}(250$ $\mathrm{mg} / \mathrm{l}$ ). The second (S2) was obtained by direct capture of $\mathrm{CO}_{2}$ via ionic dissociation in a concentrated $\mathrm{NaOH}$ solution $(2 \mathrm{M})$. Herein, 50 bars of $\mathrm{CO}_{2}(2 \mathrm{~mol})$ were injected into a reaction titanium cell ( $2 \mathrm{l}$ of volume) at ambient temperature $\left(20^{\circ} \mathrm{C}\right)$. The $\mathrm{CO}_{2}$ consumption and temperature were in-situ monitored during about 24 hours, until a macroscopic equilibrium was reached. Then, the residual $\mathrm{CO}_{2}$ gas was removed from the reactor and the solution was recovered by simple decanting of supernatant solution $(\mathrm{pH}=8.7$ and $\mathrm{TC}=0.95 \mathrm{M})$. The main difference between the two solutions lies in the initial $\mathrm{Mg}$ concentration which is equal to $1.0910^{-2}$ for $\mathrm{S} 1$ and $10^{-6}$ for S2, a difference which can be considered as yielding quasi-negligible errors in comparison to the uncertainties in the TGA measurements. In the following, we will thus only discuss the average behavior of S1 and S2.

In each experiment, $1.5 \mathrm{ml}$ of high-alkaline solution (S1 or S2) and $100 \mathrm{mg}$ of San Carlos olivine (Fo91 and grain size $<30 \mu \mathrm{m}$ ) were placed in a Teflon reaction cell, immediately assembled into a steel autoclave and the closed autoclave was placed in a multi-oven and heated to $20{ }^{\circ} \mathrm{C}\left(\mathrm{P}_{\text {sat }}=16\right.$ bar $)$. The multi-oven included ten independent temperature compartments, allowing parallel experiments to be stopped at various olivine-fluid reaction times from 3 to 60 days. This allowed determining the serpentinization and carbonation rates of olivine under the investigated hydrothermal conditions.

At the end of the experiments, the autoclave was quenched in cold water and then disassembled. Mineral characterization of the olivine alteration was made by FESEM (Field Emission Scanning Electron Microscopy), XRD, thermogravimetric analyses (TGA) and FTIR (Fourier Transform Infra Red), revealing the presence of magnesite and mainly lizardite. The magnesite crystallites had lateral sizes in the range [5-30] microns. The determination of the lizardite particle size was more difficult due to their lamellar shape and their aggregation state. However, their lateral size never exceeded 500 nanometers. In the following of this section, we will mainly focus on the TGA results (runs 1-5 and 16-20 in Table 1, (Lafay et al., 2014)) which yield the more quantitative information on the process.

\section{B. TGA analysis}

For each reaction time, the relative mass amounts of residual olivine, produced magnesite and produced serpentine (lizardite), $P_{F}, P_{M}$ and $P_{L}$, respectively, were determined by TGA. Experimental points from runs 15 and 16-20 in Lafay et al., are plotted as a function of time in Figure 1 a, together with smoothing curves $P_{i}=a_{i} * t /\left(b_{i}+t\right)$ (as used in Lafay et al., 2014) through an average of $\mathrm{S} 1$ and $\mathrm{S} 2$ experimental points. In order to relate the measured relative mass amounts to the mole numbers of each mineral (normalized in the following to one $\mathrm{kg}$ of water), we make the following hypothesis and analysis.

First, we disregard the existence of Fe in the system, so that forsterite is used instead of olivine and the precipitated magnesite and lizardite do not contain Fe. The question of Fe will be discussed in Section V B. Secondly, we assume incongruent forsterite dissolution. Indeed, it is well-established that silicates weather incongruently, because $\mathrm{Mg}-\mathrm{O}$ bonds break upon proton attack, a process which is generally faster than the hydrolysis of Si-O bonds (Rosso and Rimstidt, 2000; Schott et al., 2009; Daval et al., 2011). We assume that the incongruent forsterite dissolution amounts to congruently dissolve a mineral of chemical formula $\mathrm{Mg}_{2} \mathrm{Si}_{1-x} \mathrm{O}_{4-2 x}$. A single adjustable parameter $x$ is thus introduced which is subsequently determined as to better represent the time evolution of the solid phase amounts. Its value will be discussed in Section V A.

The relevant dissociation equations for the three minerals are thus the following:

$$
\begin{gathered}
\mathrm{Mg}_{2} \mathrm{Si}_{1-x} \mathrm{O}_{4-2 x}+4 \mathrm{H}^{+} \rightarrow 2 \mathrm{Mg}^{2+}+(1-x) \mathrm{H}_{4} \mathrm{SiO}_{4} \\
+2 x \mathrm{H}_{2} \mathrm{O} \\
\mathrm{MgCO}_{3} \rightarrow \mathrm{Mg}^{2+}+\mathrm{CO}_{3}^{2-} \\
\mathrm{Mg}_{3} \mathrm{Si}_{2} \mathrm{O}_{5}(\mathrm{OH})_{4}+6 \mathrm{H}^{+} \rightarrow 3 \mathrm{Mg}^{2+}+2 \mathrm{H}_{4} \mathrm{SiO}_{4}+\mathrm{H}_{2} \mathrm{O}
\end{gathered}
$$

At time $t$, the mole numbers of remaining and dissolved $\mathrm{Mg}_{2} \mathrm{Si}_{1-x} \mathrm{O}_{4-2 x}$, and precipitated magnesite and lizardite, noted $N_{F}(t), \delta N_{F}(t), N_{M}(t)$ and $N_{L}(t)$, respectively, are thus linked to the relative mass amounts of each mineral $P_{i}$ by the relationships:

$$
\begin{gathered}
P_{F}=\left(m_{F} N_{0}-m_{F}^{\prime} \delta N_{F}\right) / M_{t o t} \\
P_{M}=m_{M} N_{M} / M_{t o t}
\end{gathered}
$$




$$
P_{L}=m_{L} N_{L} / M t o t
$$

with $N_{0}$ the initial mole number of forsterite, $M_{t o t}=$ $m_{F} N_{0}-m_{F}^{\prime} \delta N_{F}+m_{M} N_{M}+m_{L} N_{L}$, and $m_{F}, m_{M}$, $m_{L}$ and $m_{F}^{\prime}$ the molar masses of forsterite, magnesite, lizardite and $\mathrm{Mg}_{2} \mathrm{Si}_{1-x} \mathrm{O}_{4-2 x}$, respectively. The molar masses can be obtained from mineral data bases, and at each time, only two independent quantities can be derived from the experimental results, e.g.:

$$
\begin{gathered}
\alpha=m_{F} P_{M} / m_{M} P_{F}=N_{M} /\left(N_{0}-\left(m_{F}^{\prime} / m_{F}\right) \delta N_{F}\right) \\
\beta=m_{F} P_{L} / m_{L} P_{F}=N_{L} /\left(N_{0}-\left(m_{F}^{\prime} / m_{F}\right) \delta N_{F}\right)
\end{gathered}
$$

The time evolutions of $\delta N_{F}(t)$, of the $N_{i}(t)$, and of the concentrations $c_{M g}(t)$ and $c_{S i}(t)$ of $\mathrm{Mg}$ and $\mathrm{Si}$ in the aqueous solution are then given by the set of equations:

$$
\begin{gathered}
N_{F}(t)=N_{0}-\delta N_{F}(t) \\
N_{M}(t)=\alpha(t)\left(N_{0}-\left(m_{F}^{\prime} / m_{F}\right) \delta N_{F}(t)\right) \\
N_{L}(t)=\beta(t)\left(N_{0}-\left(m_{F}^{\prime} / m_{F}\right) \delta N_{F}(t)\right) \\
c_{M g}(t)=2 \delta N_{F}(t)-N_{M}(t)-3 N_{L}(t) \\
c_{S i}(t)=(1-x) \delta N_{F}(t)-2 N_{L}(t)
\end{gathered}
$$

If $c_{S i}$ exceeds $\mathrm{SiO}_{2}$ solubility, some solid $\mathrm{SiO}_{2}$ phase may precipitate (with mole number $N_{\mathrm{SiO} 2}$ ) and $c_{S i}$ has to be replaced by $c_{\mathrm{Si}}+\mathrm{N}_{\mathrm{SiO} 2}$ in Equation 4 .

Considering that the ratios $\alpha$ and $\beta$ are known from the TGA measurements, this is a set of five equations for six (possibly seven) unknowns. To be able to solve it, we add the condition that $c_{M g}(t)=0$, following the wellknown observation that, under hydrothermal conditions in silicate rocks, $\mathrm{Mg}$ is always nearly completely incorporated into the solid phases (Fournier and Potter, 1979; Michard, 1979; Fritz, 1981). The NANOKIN results presented in the next section will confirm the validity of this hypothesis.

Figure $1 \mathrm{~b}$ displays the time evolution of $N_{F}, N_{M}$ and $N_{L}$ for a value of $x$ equal to 0.15 . Temporarily, the concentration of $\mathrm{Si}$ in the aqueous solution (maximum 0.038 moles $/ \mathrm{kg} \mathrm{H}_{2} \mathrm{O}$ ) slightly exceeds the solubility of amorphous silica, equal to 0.0155 moles $/ \mathrm{kg} \mathrm{H}_{2} \mathrm{O}$ at $\mathrm{T}=200^{\circ} \mathrm{C}$, thus leaving the possibility that some amount of $\mathrm{SiO}_{2}$ polymorph might precipitate. Such precipitation was not observed experimentally neither by FESEM at $t=60$ days, nor by TGA at all times, due to the small amounts involved, and the limited analytical sensitivity.

\section{NUMERICAL SIMULATION}

\section{A. Method: the NANOKIN code}

The simulation of olivine alteration in the batch reactor at $\mathrm{T}=200{ }^{\circ} \mathrm{C}$ and under constant gaseous volume conditions, was performed with the help of the NANOKIN code (Noguera et al., 2006a,b; Fritz et al., 2009). It includes a full treatment of speciation processes in the aqueous solution, a rate equation for the dissolution of
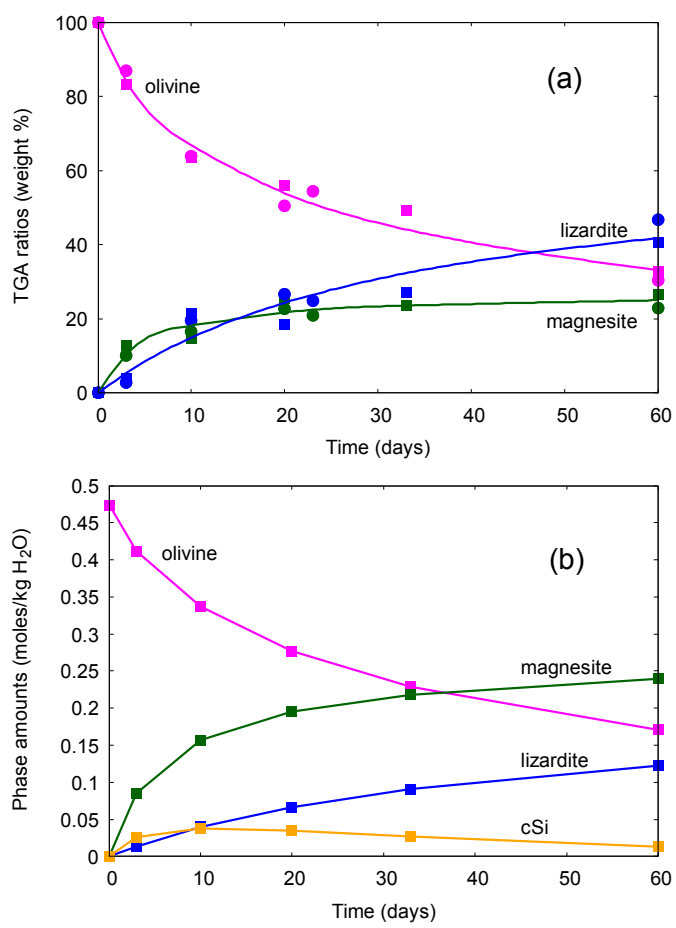

FIG. 1: a): Time evolution of TGA ratios (\%) $P_{F}, P_{M}, P_{L}$ of olivine (forsterite), magnesite and lizardite, respectively, from runs 1-5 and 16-20 in Lafay et al., 2014; b): time evolution of their corresponding mole numbers (normalized to $1 \mathrm{~kg} \mathrm{H}_{2} \mathrm{O}$ ) $N_{F}, N_{M}, \mathrm{~N}_{L}$, and $\mathrm{Si}$ concentration in solution, issued from the resolution of Equation 4, assuming $x=0.15$ (see text). Lines are drawn to guide the eyes.

forsterite deduced from the TGA analysis (see following section), and a full account of nucleation and growth processes during the formation of magnesite and lizardite (and possibly $\mathrm{SiO}_{2}$ ).

Simulation is performed assuming constant gaseous volume $V=1$ liter in the reactor, including gaseous $\mathrm{CO}_{2}$ and water vapor. The system is closed, so that there is conservation of the total amount of carbon (including gaseous $\mathrm{CO}_{2}$, aqueous carbon species and carbon contained in the magnesite phase). The $\mathrm{CO}_{2}$ gaseous phase is described by a van der Waals gas state equation (Fritz et al., 2013) $\left(P+n^{2} a^{\prime} / V^{2}\right) *\left(V-n b^{\prime}\right)=n R T$ in which $P, V, T$ and $n$ are the partial pressure, volume, temperature and mole number, respectively, $R$ the perfect gas constant, $a^{\prime}=0.364 \mathrm{~Pa} . \mathrm{m}^{6} \cdot \mathrm{mol}^{-2}$ and $b^{\prime}=4.27 \times 10^{-5}$ $\mathrm{m}^{3} \cdot \mathrm{mol}^{-1} \cdot \mathrm{CO}_{2}$ gas is assumed to be in equilibrium with the aqueous solution at each time.

The treatment of precipitation relies on the theoretical approach of nucleation, growth and/or resorption of particles of fixed composition in aqueous solutions at constant temperature, that we have developed in the past (Noguera et al., 2006a,b; Fritz et al., 2009). The saturation state $I$ of the aqueous solution with respect to each newly formed phase, represents the driving force for its precipitation if $I>1$. The method combines the classical theory of particle nucleation (Adamson, 1960; Markov, 
1995) with a size dependent growth law allowing particle growth and/or resorption, and thus Ostwald ripening effects (Noguera et al., 2006a,b; Fritz et al., 2009). For each three dimensional secondary mineral (magnesite, amorphous silica), the number of formula units $n^{*}$ in the critical nuclei and the nucleation barrier $\Delta G^{*}$ read:

$$
n^{*}=\frac{2 u}{\ln ^{3} I} \quad ; \quad \frac{\Delta G^{*}}{k_{B} T}=\frac{u}{\ln ^{2} I} \quad \text { with } \quad u=\frac{X v^{2} \sigma^{3}}{\left(k_{B} T\right)^{3}}
$$

In these expressions, $\sigma$ is the mean surface energy, $v$ the volume of one formula unit, and $k_{B}$ is related to $R$ and the Avogadro number $\mathcal{N}_{A v}$ by $k_{B}=R / \mathcal{N}_{A v}$. The geometrical parameter $X$ is equal to $X=32$ for magnesite particles and $X=16 \pi / 3$ for amorphous silica spherical particles. Lizardite particles have the shape of platelets of thickness $e=7 \AA$ and their growth is considered to be two dimensional. In this case, $n^{*}$ and $\Delta G^{*}$ read (Fritz et al., 2009):

$$
n^{*}=\frac{u}{\ln ^{2} I} \quad ; \quad \frac{\Delta G^{*}}{k_{B} T}=\frac{u}{\ln I} \quad \text { with } \quad u=\frac{2 \sqrt{3} e v \sigma^{2}}{\left(k_{B} T\right)^{2}}
$$

The nucleation rate $F$ is assumed to vary exponentially with the nucleation barrier, with a constant pre-factor $F_{0}$ :

$$
F=F_{0} \exp \left(-\frac{\Delta G^{*}}{k_{B} T}\right)
$$

$F$ becomes significant $\left(F>1\right.$ particle/s/ $\left./ \mathrm{kg} \mathrm{H}_{2} \mathrm{O}\right)$ for a given mineral only when $I$ exceeds a critical value $I_{c}$. For example, for lizardite, $I_{c}$ reads:

$$
\ln I_{c}=\frac{2 \sqrt{3} e v \sigma^{2}}{\left(k_{B} T\right)^{2} \ln F_{0}}
$$

Once formed and as the saturation state of the solution evolves with time, the particles experience growth or resorption, depending upon the relative value of their size and the instantaneous critical nucleus size.

$$
\frac{d l}{d t}=\kappa\left[I-\exp \left(\frac{2 u}{n}\right)^{1 / 3}\right]
$$

for $3 \mathrm{D}$ particles such as magnesite and $\mathrm{SiO}_{2}$ and:

$$
\frac{d l}{d t}=\kappa\left[I-\exp \left(\frac{u}{n}\right)^{1 / 2}\right]
$$

for $2 \mathrm{D}$ lizardite particles. In these growth equations, $l$ represents the lateral size of magnesite or lizardite particles or the radius of $\mathrm{SiO}_{2}$ particles. From this, the time dependence $l\left(t_{1}, t\right)$ for any particle nucleated at time $t_{1}$ can be obtained. Finally, in the closed system upon consideration, nucleation and growth exert a feed-back effect on the aqueous solution modifying its saturation state. At time $t$, the total mole number $N_{i}(t)$ of the secondary phases $i$ which have changed phase, is equal to:

$$
N_{i}(t)=\mathcal{N}_{A v} \int_{0}^{t} F_{i}\left(t_{1}\right)\left(n_{i}\left(t_{1}, t\right)-1\right) d t_{1}
$$

From the knowledge of $N_{i}(t)$, the amount of dissolved forsterite, the conservation equations for magnesium, silicon and carbon and the electrical neutrality, it is possible to calculate the activity of all ions in solution, using published aqueous speciation databases (Helgeson et al., 1970; Parkhurst and Appello, 1999; Blanc et al., 2012), and thus deduce the value of the saturation states $I_{i}$ with respect to each mineral at the next time step using published databases for solubility products (Blanc et al., 2012). The instantaneous values of the saturation indexes of the solution $I_{i}(t)$ are the key parameters which drive the size evolution of stable/unstable particles and the model keeps track of all particles in the system.

\section{B. Discussion of the nucleation and growth parameters}

Aside from solubility products and speciation data which may be found in data bases, three parameters determine the kinetic behavior of each mineral, namely the surface energy $\sigma$, the pre-factor of the nucleation rate $F_{0}$, and the growth constant $\kappa$. Since there is no data base available for these parameters, we have determined them via a fit to the experimental results (Figure 1b and particle sizes at the end of the experiment). It should be understood that such a fit is extremely challenging due to its highly non-linear character. Variations of one of the parameters induce modifications of all observables. Additionally, in the present study, as will be explained in Section V C, Mg and Si species are shared between several minerals, making the kinetic behavior of magnesite, lizardite and $\mathrm{SiO}_{2}$ phases very intricate. So, although there is no certainty that a unique solution exists, the parameter determination is extremely constrained.

To our knowledge, there are no tabulated values for the mean surface energies of lizardite and magnesite in contact with an aqueous medium. For magnesite, the value $\sigma_{M}=0.105 \mathrm{~J} / \mathrm{m}^{2}$ was determined by comparison with the value $0.097 \mathrm{~J} / \mathrm{m}^{2}$ relevant for calcite (Nielsen and Söhnel, 1971), on the basis of the quasi-linear relationship established by these authors (Nielsen and Söhnel, 1971; Söhnel, 1982) between surface energies and the logarithm of the solubility products of many minerals. The mean surface energy of lizardite was expected to be close to those of other silicates (kaolinite, muscovite, clays) of the order of $0.1 \mathrm{~J} / \mathrm{m}^{2}$ (Fritz et al., 2009). However, compared to kaolinite, the lizardite particles have a brucite-like termination instead of a gibbsite-like one. First-principles determinations of the surface energies of brucite and gibbsite basal surfaces demonstrate that the former is lower than the latter (Churakov et al., 2004; Fleming et al., 2000). Using this guideline, we have tentatively taken for $\sigma_{L}$ a value $\left(0.085 \mathrm{~J} / \mathrm{m}^{2}\right)$ smaller than the one we had used for kaolinite. Together with the value of $F_{0}$ (to be discussed below), it yields a critical value $I_{c}$ for the saturation state of the aqueous solution, Equation 8, which allows lizardite to start precipitating 

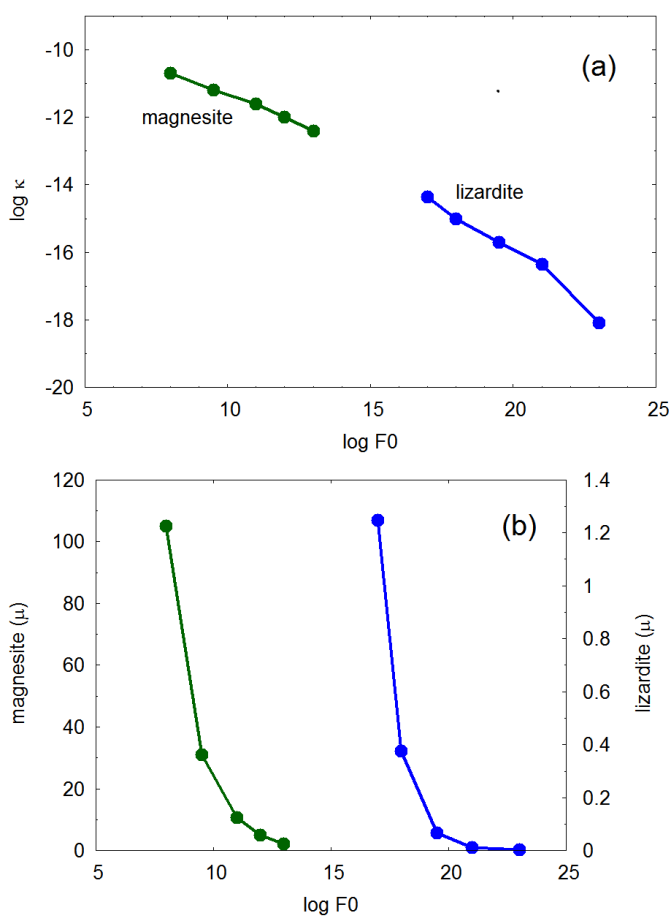

FIG. 2: a): Log-log correlation between $F_{0}$ and $\kappa$ values allowing a good agreement with TGA curves, for magnesite (green) and lizardite (blue). b: mean particle sizes of magnesite (green line) and lizardite (blue line) at time $t=60$ days, as a function of $\log F_{0}$ obtained with the associated $\kappa$ values of the top panel.

before $t=3$ days, in agreement with experiment.

Once the magnesite and lizardite mean surface energies were fixed, their parameters $\left\{F_{0}, \kappa\right\}$ had to be determined. It was found that for each mineral, similar kinetic behaviors could be found, provided that $\left\{F_{0}, \kappa\right\}$ are coupled. Figure 2a displays the relationship between them which allows obtaining the best agreement with TGA data. Interestingly, in this log-log plot, the slopes of the curves for magnesite and lizardite are different and close to $-1 / 3$ for the former and $-1 / 2$ for the latter. This may be understood by noting that, qualitatively, the volume of precipitated matter is proportional to $F_{0} * l^{3}$, i.e. $F_{0} * \kappa^{3}$ for magnesite (3D growth) and $F_{0} * l^{2}$, i.e. $F_{0} * \kappa^{2}$ for lizardite (2D growth), in particular at the end of the experiment.

To go one step further, among the coupled $\left\{F_{0}, \kappa\right\}$ values displayed in Figure 2a, we chose those yielding correct particle sizes at $t=60$ days. Figure $2 \mathrm{~b}$ shows how, for each mineral, the final mean particle sizes vary as a function of $\log F_{0}$. The rapid variations displayed on this figure allowed to fix the value of the prefactor $F_{0}$ of the nucleation rate for both minerals, with a relative precision, and the growth constants $\kappa$ were subsequently determined by using the correlation represented in Figure 2 a.

The values of $F_{0}\left(F_{0}=10^{11}\right.$ particles $/ \mathrm{s} / \mathrm{kg} \mathrm{H}_{2} \mathrm{O}$ for magnesite and $F_{0}=10^{18}$ particles $/ \mathrm{s} / \mathrm{kg} \mathrm{H}_{2} \mathrm{O}$ for lizardite) are rather small compared to typical values found in the literature. However, one should remember that, before being attached to the critical nuclei, the growth units have to break their bonds with the solvent molecules. The solvation energy $\Delta U$ of the ions has thus to be supplied, which enters the expression of $F_{0} \propto \exp -\left(\Delta U / k_{B} T\right)$ (Markov, 1995). $\Delta U$ is particularly high for magnesium ions $(455.5 \mathrm{kcal} / \mathrm{mole}$, Jolivet, 2016 ), which rationalizes the relatively small values of $F_{0}$ for lizardite and magnesite.

The lizardite growth constants deduced from the above procedure are somewhat different from values found in the literature (Sverdrup, 1999; Palandri and Kharaka, 2004). However, one should remember that all previous evaluations have been done on the basis of an Arrhenius law for their temperature dependence, with activity energies which are likely not very precise, especially in the temperature range around $200^{\circ} \mathrm{C}$. The magnesite growth constant is in qualitative agreement with previous determination considering the uncertainty in the limit between acidic-neutral and alkaline ranges at $200^{\circ} \mathrm{C}$.

\section{RESULTS}

\section{A. Aqueous solution heating to $200^{\circ} \mathrm{C}$}

As a first step to simulate experimental conditions, the S1 solution is progressively heated up to $200^{\circ} \mathrm{C}$ by successive small temperature increases $\left(\Delta T \leq 0.1^{\circ} \mathrm{C}\right)$. At each step, thermodynamic equilibrium is imposed, using the temperature dependence of the speciation constants and solubility products. Total pressure, water partial pressure and $\mathrm{CO}_{2}$ partial pressure in the reactor become equal to 23.5 bars, 15.54 bars and 7.97 bars, respectively. The $\mathrm{pH}$ in the aqueous solution decreases down to $\mathrm{pH} \approx 7$, a still alkaline $\mathrm{pH}$, considering that neutrality at $\mathrm{T}=200^{\circ} \mathrm{C}$ is obtained at $\mathrm{pH} \approx 5.6$. A very small amount of magnesite (0.01 mole) already precipitates during the temperature rise. This early magnesite precipitation makes the solution $\mathrm{S} 1$ very similar to $\mathrm{S} 2$ in the first minutes of the experiment. Eventually, we add it to the amount formed by subsequent nucleation and growth processes (see the following).

\section{B. Nucleation and growth simulation}

The characteristics of the aqueous solution S1 at $\mathrm{T}=200^{\circ} \mathrm{C}$ just discussed are used as starting values for the NANOKIN simulation of precipitation. The forsterite dissolution law was adjusted to the results of the TGA analysis shown in Figure 1. It is well accounted for by a second order law as proposed in Lafay et al. (2014). This amounts to writing $\delta N_{F}(t)=a t /(b+t)$. Table 1 gives the values of the parameters entered in the simulation and Figure 3, 4, and 5 show the time evolution 


\begin{tabular}{|l|l|l|l|l|}
\hline & forsterite & magnesite & lizardite & amorphous silica \\
\hline $\log \mathrm{K}$ & 14.59 & -11.72 & 17.55 & -1.808 \\
$\kappa(\mathrm{m} / \mathrm{s})$ & - & $2.5^{*} 10^{-12}$ & $1 .^{*} 10^{-15}$ & $1.7^{*} 10^{-14}$ \\
$\mathrm{v}\left(\AA^{3}\right)$ & - & 46.9 & 174 & 48.15 \\
$\sigma\left(\mathrm{J} / \mathrm{m}^{2}\right)$ & - & 0.105 & 0.085 & 0.022 \\
$\mathrm{~F}_{0}\left(/ \mathrm{s} / \mathrm{kg} \mathrm{H} \mathrm{H}_{2} \mathrm{O}\right)$ & - & $10^{11}$ & $10^{18}$ & $10^{23}$ \\
\hline
\end{tabular}

TABLE 1: Parameters used in the simulation: solubility products $K$, growth constant $\kappa$, volume of the formula unit $v$ (Webmineral, 2014), mean surface energy $\sigma$, and prefactor of the nucleation frequency $F_{0}$. The parameter of congruence $x=0.15$ and the $a$ and $b$ coefficients of the forsterite dissolution rate are equal to $a=0.392$ mole $* \mathrm{~s}$ and $b=1.63 * 10^{6} \mathrm{~s}$. The initial amount of forsterite is $N_{0}=0.474$ mole $/ \mathrm{kg} \mathrm{H}_{2} \mathrm{O}$; initial $\mathrm{pH}=6.99$; initial $p_{\mathrm{CO}_{2}}=7.97$ bars.
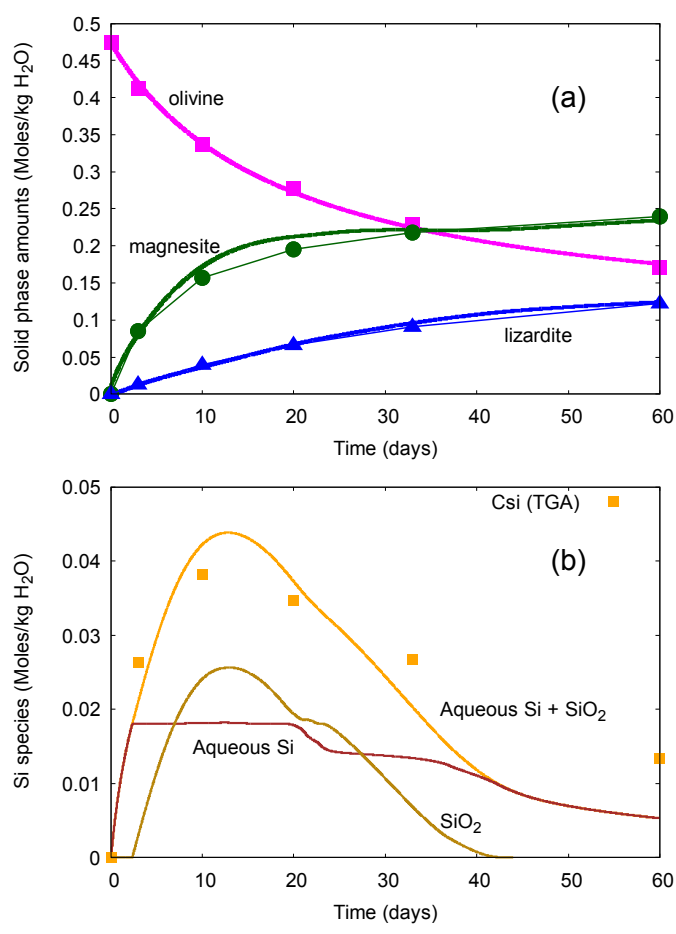

FIG. 3: a): time evolution of the amounts of forsterite, magnesite and lizardite obtained from NANOKIN simulations (thick lines) and from the TGA analysis (symbols and thin lines); b): time evolution of the amounts of amorphous silica, $\mathrm{Si}$ concentration in aqueous solution and their sum (lines), compared to TGA results for the latter (dots).

of the solid phase amounts, of the aqueous solution characteristics and $\mathrm{CO}_{2}$ pressure, and of the particle sizes, respectively.

Figure 3a compares the amounts of forsterite, magnesite and lizardite to the values extracted from TGA, at each time. One can see that the agreement is excellent. The precipitation of magnesite starts much more rapidly than that of lizardite. After sixty days, nearly half of the initial forsterite amount remains and the pre-
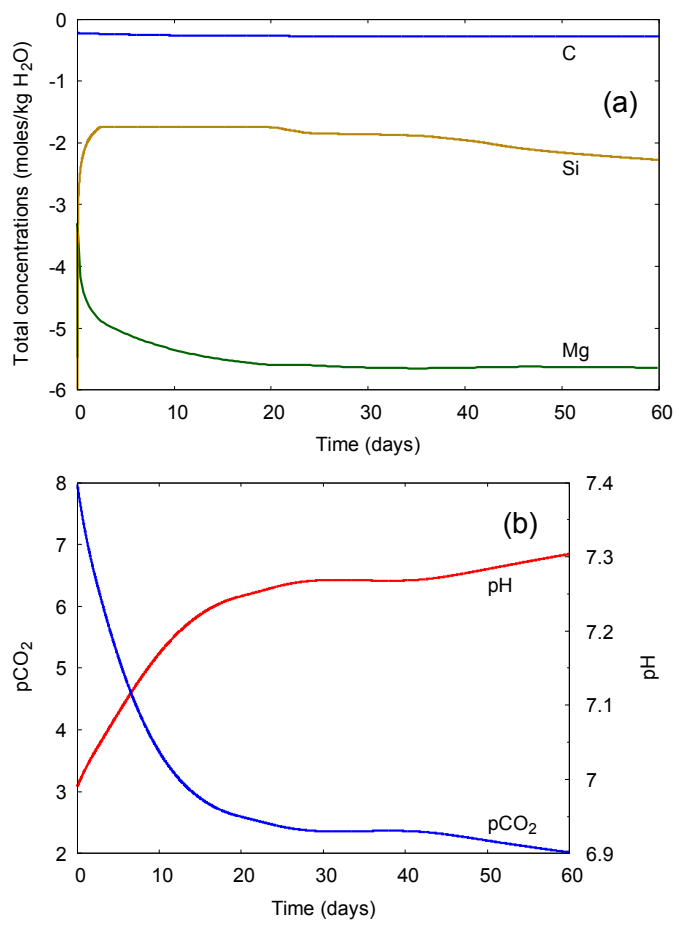

FIG. 4: a): time evolution of the concentration of elements in the aqueous solution (log scale); b): $\mathrm{pH}$ in the aqueous solution and $\mathrm{CO}_{2}$ pressure $p_{\mathrm{CO}_{2}}$ from NANOKIN simulation.

cipitation process is still going on. Moreover, despite the incongruent forsterite dissolution which reduces the $\mathrm{Si}$ amounts released in the aqueous solution, the simulation highlights the existence of transitory $\mathrm{SiO}_{2}$ precipitation, not observed experimentally (Figure 3b). As discussed in more details in Section $\mathrm{V}$ A, the present modeling assumes that it consists in amorphous silica.

Figure 4 shows the time evolution of the element concentrations in the aqueous solution, of the $\mathrm{pH}$ and of the $\mathrm{CO}_{2}$ partial pressure $p_{\mathrm{CO}_{2}}$. As expected from the magnesite precipitation, there is a consumption of carbon, which mainly concerns the $\mathrm{CO}_{2}$ gas phase, while its concentration in the aqueous solution remains approximately constant. The aqueous solution is thus buffered with respect to carbonates and the $\mathrm{CO}_{2}$ pressure strongly decreases as a function of time from 8 to less than 2 bars. The small increase of $\mathrm{pH}$ with time is the result of competing effects: consumption of protons for the alteration of olivine and production of protons due to $\mathrm{CO}_{2}$ gas dissolution. The $\mathrm{Mg}$ concentration remains of the order of $10^{-5.5}$ during the whole precipitation process, showing that the $\mathrm{Mg}$ produced by the dissolution of forsterite is immediately incorporated into the magnesite and lizardite particles. This a posteriori justifies the hypothesis made in the TGA analysis (Section IIB). Silicon concentration first increases due to the dissolution of forsterite before lizardite starts precipitating, and then decreases when the latter becomes significant.

The time evolution of the magnesite and lizardite mean 


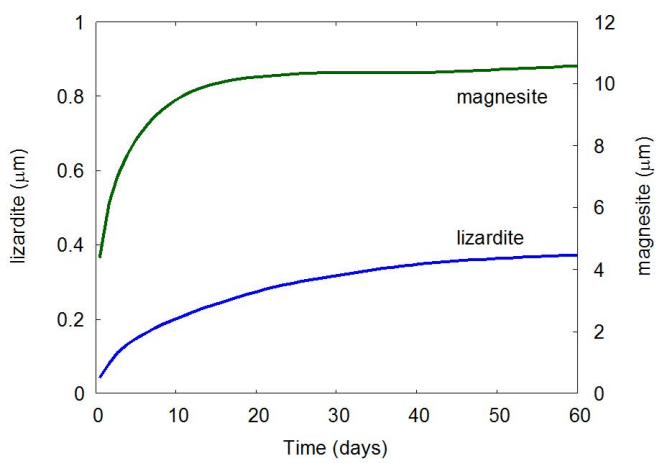

FIG. 5: Time evolution of the mean particle size of lizardite (left scale) and magnesite (right scale) (microns).

particle sizes is displayed in Figure 5. While both monotonically increase with time, their values strongly differ. Magnesite particles reach about 10 microns in size. At variance, the lizardite particles remain small with a mean size which does not exceed $400 \mathrm{~nm}$ after sixty days, in good qualitative agreement with FESEM observations.

\section{Summary}

The simulation of the kinetic precipitation of lizardite and magnesite from olivine alteration that we have performed succeeds in quantitatively reproducing both experimental TGA results and mean particle sizes observed with FESEM. It also brings additional information which complement the experimental results. It stresses that the in-situ $\mathrm{pH}$ value at $200^{\circ} \mathrm{C}$ is much lower, albeit still alkaline, than in the state of the aqueous solution prepared at ambient temperature (ex-situ value equal to 8.7-8.9). It gives information on the silicon status during precipitation, including the incongruent dissolution, the possible precipitation of an $\mathrm{SiO}_{2}$ solid phase and the $\mathrm{H}_{4} \mathrm{SiO}_{4}$ presence in the aqueous solution. It confirms that all the magnesium released by the dissolution of olivine is incorporated in the magnesite and lizardite phases.

Moreover, thanks to the possibility of changing the input parameters, the simulation tool allows analyzing the mechanism of competition of lizardite and magnesite, which will be discussed in Section V C.

\section{DISCUSSION}

In this section, we first discuss the silicon status during precipitation, including the incongruent forsterite dissolution, the possible precipitation of an $\mathrm{SiO}_{2}$ solid phase and the $\mathrm{H}_{4} \mathrm{SiO}_{4}$ presence in the aqueous solution (Section $\mathrm{VA}$ ). We then make a preliminary attempt to take into account the Fe content of the San Carlos olivine (Section VB). Finally, we discuss the competition between lizardite, magnesite and $\mathrm{SiO}_{2}$ (Section $\mathrm{VC}$ ).

\section{A. Incongruent forsterite dissolution, $\mathrm{H}_{4} \mathrm{SiO}_{4}$ in solution and $\mathrm{SiO}_{2}$ precipitation}

The resolution of the set of equations 4 gives information on the silicon concentration $c_{S i}(t)$ available in the aqueous solution as a result of olivine dissolution. It significantly depends on the hypothesis made on the degree of incongruence $x$ of olivine dissolution. However, for all reasonable values of $x$ (typically less than 0.2 ), and especially $x=0$, it is found that, in some time interval, $c_{S i}(t)$ exceeds the solubility of amorphous silica $\left(0.0155\right.$ moles $/ \mathrm{kg} \mathrm{H}_{2} \mathrm{O}$ at $\left.\mathrm{T}=200^{\circ} \mathrm{C}\right)$. Considering that, at this temperature, other $\mathrm{SiO}_{2}$ polymorphs (cristobalite, chalcedony or quartz) have smaller solubility products (e.g. cristobalite 0.0121 moles $/ \mathrm{kg} \mathrm{H}_{2} \mathrm{O}$, chalcedony 0.0055 moles $/ \mathrm{kg} \mathrm{H}_{2} \mathrm{O}$, quartz 0.0037 moles $/ \mathrm{kg}$ $\mathrm{H}_{2} \mathrm{O}$ (Blanc et al., 2012)), it is likely that at least one of them precipitates during olivine alteration. This phase may be detected neither by TGA analysis nor by FESEM if it remains in very tiny amount.

Relying on the relationship between solubility products and surface energies (Nielsen and Söhnel, 1971; Söhnel, 1982), amorphous silica should have the lowest surface energy and thus should be the fastest polymorph to precipitate. This is why we have assumed that the solid $\mathrm{SiO}_{2}$ phase mainly consists in amorphous silica. Its mean surface energy $\sigma$ and $F_{0}$ nucleation prefactor were extrapolated from those which accounted for amorphous silica precipitation as a function of time (Noguera et al., 2015).

As far as the $x$ parameter is concerned, we noted that, if $x$ is too small, it is impossible to obtain a good fit to experiment. Indeed, if the short time behavior of magnesite is well reproduced, its long term behavior is incorrect, as shown in Figure 6 when $x=0$. Moreover, at the end of the experiment, $\mathrm{SiO}_{2}$ particles are still present, which should have been detected by FESEM. We propose a value of the order of $x=0.15$. It allows a good fit to the TGA curves, is consistent with no $\mathrm{SiO}_{2}$ particles at $t=60$ days, and agrees with the numerous observations that the dissolution of silicates is incongruent.

\section{B. Account of Fe}

Up to this point, we have disregarded the existence of the $9 \%$ substitution of $\mathrm{Mg}$ by Fe in the San Carlos olivine. In reality, during the olivine alteration, Fe is released in the aqueous solution and incorporated in the secondary minerals magnesite and lizardite. In order to account for the Fe balance in the system, despite insufficient detailed experimental information on its partitioning, in the following, we will assume that the secondary phases contain the same $\mathrm{Fe} / \mathrm{Mg}$ proportion as olivine.

The dissociation equations for the three minerals then 


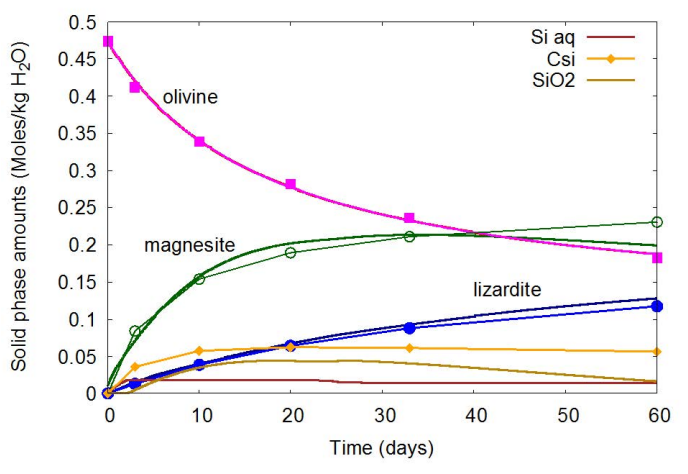

FIG. 6: Time evolution of the amounts of solid phases and $\mathrm{Si}$ aqueous concentration obtained from NANOKIN simulations (thick lines) and from the TGA analysis (symbols and thin lines) upon the assumption of congruent dissolution of forsterite $(x=0)$.

read:

$$
\begin{gathered}
\mathrm{Mg}_{1.82} \mathrm{Fe}_{0.18} \mathrm{Si}_{1-x} \mathrm{O}_{4-2 x}+4 \mathrm{H}^{+} \rightarrow \\
1.82 \mathrm{Mg}^{2+}+0.18 \mathrm{Fe}^{2+}+(1-x) \mathrm{H}_{4} \mathrm{SiO}_{4}+2 x \mathrm{H}_{2} \mathrm{O} \\
\mathrm{Mg}_{0.91} \mathrm{Fe}_{0.09} \mathrm{CO}_{3} \rightarrow \\
0.91 \mathrm{Mg}^{2+}+0.09 \mathrm{Fe}^{2+}+\mathrm{CO}_{3}^{2-} \\
\mathrm{Mg}_{2.73} \mathrm{Fe}_{0.27} \mathrm{Si}_{2} \mathrm{O}_{5}(\mathrm{OH})_{4}+6 \mathrm{H}^{+} \rightarrow \\
2.73 \mathrm{Mg}^{2+}+0.27 \mathrm{Fe}^{2+}+2 \mathrm{H}_{4} \mathrm{SiO}_{4}+\mathrm{H}_{2} \mathrm{O}
\end{gathered}
$$

The TGA analysis only allows to determine the two independent quantities $\alpha$ and $\beta$ as before, with a mere modification of the molar masses $m_{F}, m_{M}, m_{L}$ and $m_{F}^{\prime}$ of the solid phases. The resulting time evolutions of $\delta N_{F}(t)$, the $N_{i}(t)$, and of the concentrations $c_{M g}(t), c_{F e}(t)$ and $c_{S i}(t)$ of $\mathrm{Mg}, \mathrm{Fe}$ and $\mathrm{Si}$ in the aqueous solution are thus given by the set of equations:

$$
\begin{gathered}
N_{F}(t)=N_{0}-\delta N_{F}(t) \\
N_{M}(t)=\alpha(t)\left(N_{0}-\left(m_{F}^{\prime} / m_{F}\right) \delta N_{F}(t)\right) \\
N_{L}(t)=\beta(t)\left(N_{0}-\left(m_{F}^{\prime} / m_{F}\right) \delta N_{F}(t)\right) \\
c_{M g}(t)=1.82 \delta N_{F}(t)-0.91 N_{M}(t)-2.73 N_{L}(t) \\
c_{F e}(t)=0.18 \delta N_{F}(t)-0.09 N_{M}(t)-0.27 N_{L}(t) \\
c_{S i}(t)+N_{S i O_{2}}=(1-x) \delta N_{F}(t)-2 N_{L}(t)
\end{gathered}
$$

The resolution of these equations proceeds as in the absence of $\mathrm{Fe}$, with the additional assumption that $c_{F e}(t) \approx$ 0 in the aqueous solution, which will be numerically confirmed. The time evolution of $N_{F}, N_{M}, N_{L}$ and $N_{S i O 2}$ issued from the experiment is very similar to that displayed in Figure 1. The amount of dissolved olivine $\delta N_{L}$ again follows a second order reaction law with $a$ and $b$ coefficients slightly different from before, and the aqueous solution at some point becomes oversaturated with respect to amorphous silica.
The incorporation of Fe changes the solubility products with respect to the pure minerals. Considering that, under the present conditions, the mixing is less than $10 \%$, we have used the ideal solid solution expression for the stoichiometric solubility product of an $\mathrm{A}_{1-z} \mathrm{~B}_{z} \mathrm{C}$ solid solution as a function of the solubility products $K_{A C}$ and $K_{B C}$ of its end-members (Noguera et al., 2010; Noguera et al., 2016):

$$
K(z)=K_{A C}^{1-z} K_{B C}^{z} z^{z}(1-z)^{(1-z)}
$$

In the present case, we use magnesite and siderite $\mathrm{FeCO}_{3}$ as end-members of $\mathrm{Mg}_{1-z} \mathrm{Fe}_{z} \mathrm{CO}_{3}$ and lizardite and greenalite $\mathrm{Fe}_{3} \mathrm{Si}_{2} \mathrm{O}_{5}(\mathrm{OH})_{4}$ as end-members of $\left(\mathrm{Mg}_{1-z} \mathrm{Fe}_{z}\right)_{3} \mathrm{Si}_{2} \mathrm{O}_{5}(\mathrm{OH})_{4}$. At $200^{\circ} \mathrm{C}$, the solubility products of siderite $\mathrm{FeCO}_{3}$ and greenalite $\mathrm{Fe}_{3} \mathrm{Si}_{2} \mathrm{O}_{5}(\mathrm{OH})_{4}$ are respectively equal to $\log \mathrm{K}=-13.29$ and $\log \mathrm{K}=10.60$ (Blanc et al., 2012), which leads to $\log K$ values of the solid solutions equal to -11.99 and 16.79 for magnesite and lizardite, respectively.

As far as elementary volumes are concerned, a 100\% replacement of $\mathrm{Mg}^{2+}$ by $\mathrm{Fe}^{2+}$ in magnesite and lizardite leads to an increase of volume of about 10\% (Webmineral, 2014). Consequently $9 \%$ replacement should be associated to not more than $1 \%$ volume increase. We have neglected it since it would lead to corrections smaller than the experimental error bars.

On the basis of the quasi-linear relationship established by Söhnel (Nielsen and Söhnel, 1971; Söhnel, 1982) between surface energies and the logarithm of solubility products, we have accordingly modified the values of $\sigma$ for the magnesite and lizardite $\left(\sigma=0.110 \mathrm{~J} / \mathrm{m}^{2}\right.$ and 0.100 $\mathrm{J} / \mathrm{m}^{2}$, respectively, to be compared with previous values 0.105 and $0.085 \mathrm{~J} / \mathrm{m}^{2}$ ). No modification of $F_{0}$ was necessary for the former while only a small one for the latter $\left(F_{0}=3 . * 10^{18}\right)$ led to the excellent agreement shown in Figure 7. We checked that the Fe concentration in the aqueous solution never exceeds $10^{-5}$ moles, which a posteriori justifies the approximation $\left(c_{F e} \approx 0\right)$ that we made that the amount of aqueous iron is negligible with respect to that produced by the forsterite dissolution and precipitated by the secondary phases. The mean particle sizes at the end of the experiment are $375 \mathrm{~nm}$ and 15 microns for lizardite and magnesite, respectively.

To summarize, within this treatment of precipitation which includes iron incorporation in magnesite and lizardite, most kinetic parameter values that we have determined are little modified with respect to those found in the absence of Fe, the fit to the experiment is as good, and, more importantly, as far as the competition between $\mathrm{SiO}_{2}$, magnesite and lizardite is concerned (see following section), the interpretation of the alteration process is unchanged.

However, it was noted in the experiment, that, according to preliminary Mossbauer measurements at $t=60$ days, roughly $50 \% \mathrm{Fe}$ had been transformed to $\mathrm{Fe}^{3+}$ (Lafay et al., 2014), suggesting that iron oxidation was also accompanied by some hydrogen gas emission. A full account of such a complex chemistry would require 


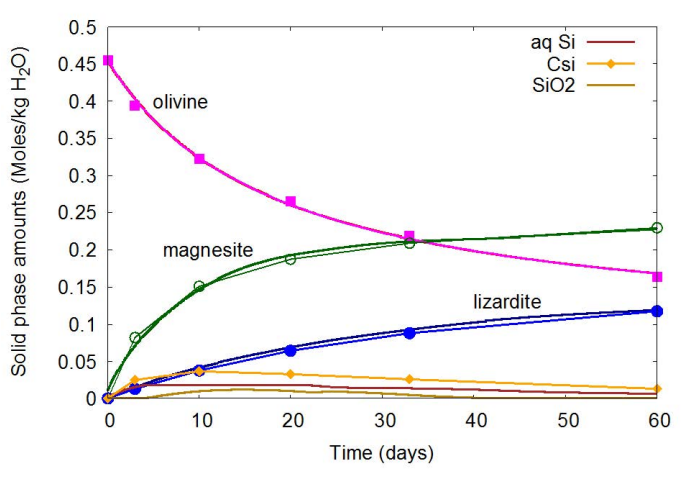

FIG. 7: Same as Figure 3a, for a NANOKIN simulation which takes into account $9 \%$ content of Fe in the dissolving olivine.

treating simultaneously the oxido-reduction processes in the aqueous solution, the hydrogen gas emission and the time dependent partition of $\mathrm{Fe}^{2+}$ and $\mathrm{Fe}^{3+}$ in the lizardite particles, but this is beyond the present capabilities of NANOKIN. Future joint experimental and numerical work will be necessary to assess the relevance of our simplified Fe treatment.

\section{Competition between lizardite, magnesite and $\mathrm{SiO}_{2}$ precipitation}

As shown in the preceding sections, we have simulated the simultaneous precipitation of lizardite and magnesite from hydrothermal alteration of forsterite under highcarbonate alkalinity, and we have been able to obtain a good agreement with experimental results. The different kinetic behaviors of lizardite and magnesite raise questions on the competitive incorporation of $\mathrm{Mg}$ and $\mathrm{Si}$ ions released by the dissolution of forsterite into the secondary phases. Our NANOKIN simulation tool allows to scrutinize the mechanism of these competitions and to highlight on which parameter they mainly rely.

The starting point is the conservation laws of $\mathrm{Mg}$ and $\mathrm{Si}$ in the system. They relate the amounts of phases produced and dissolved and the aqueous Si concentration. The Mg conservation implies:

$$
2 \delta N_{F}(t)=N_{M}(t)+3 N_{L}(t)
$$

and the Si one:

$$
c_{S i}(t)+N_{S i O 2}=(1-x) \delta N_{F}(t)-2 N_{L}(t)
$$

Equation 15 tells that any excessive magnesite precipitation induces an insufficient lizardite precipitation and vice-versa. According to Equation 16, any excessive lizardite precipitation induces a strong reduction of the available $\mathrm{Si}$ in the aqueous solution and the $\mathrm{SiO}_{2}$ solid phase. In the following we quantitatively exemplify these trends, by changing the kinetic parameters of magnesite and lizardite.
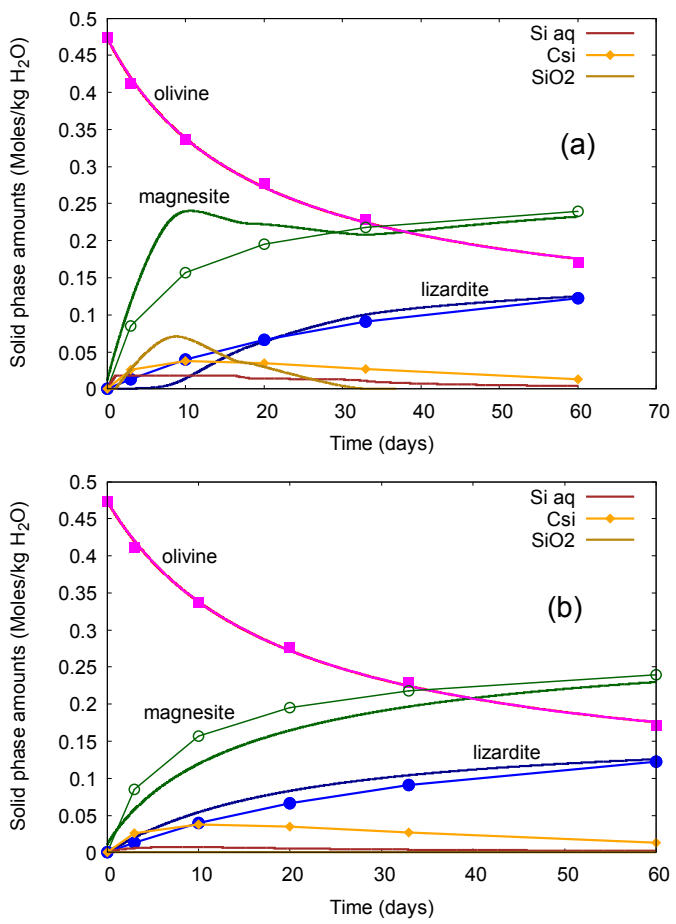

FIG. 8: Same as Figure 3a for a): an increase of magnesite nucleation frequency $F_{0}=10^{13}$ particles $/ \mathrm{s} / \mathrm{kg} \mathrm{H}_{2} \mathrm{O}$ instead of $\left.F_{0}=10^{11} ; \mathrm{b}\right)$ : an increase of lizardite nucleation frequency $F_{0}=10^{22}$ particles $/ \mathrm{s} / \mathrm{kg} \mathrm{H} \mathrm{H}_{2} \mathrm{O}$ instead of $F_{0}=10^{18}$.

Figure 8 a shows a typical example in which the magnesite nucleation rate was strongly increased $\left(F_{0}=10^{13}\right.$ particles $/ \mathrm{s} / \mathrm{kg} \mathrm{H}_{2} \mathrm{O}$ instead of $\left.F_{0}=10^{11}\right)$. Because magnesite is the mineral which starts precipitating quasi immediately, the enhancement of its nucleation rate leads to an increase of its precipitated amount in the short time and a delay of 5 to 6 days in the production of lizardite. The Si concentration released by the forsterite dissolution, not being incorporated in lizardite, consequently increases and leads to a strong precipitation of $\mathrm{SiO}_{2}$.

Similarly, an increase in the kinetic parameters of lizardite has an impact on magnesite growth and $\mathrm{Si}$ in the aqueous solution. This is exemplified in Figure $8 \mathrm{~b}$ for which the lizardite nucleation rate was strongly increased $\left(F_{0}=10^{22}\right.$ particles $/ \mathrm{s} / \mathrm{kg} \mathrm{H}_{2} \mathrm{O}$ instead of $\left.F_{0}=10^{18}\right)$. Not only is there a decrease of the aqueous silica activity and absence of $\mathrm{SiO}_{2}$ precipitation, but the amount of magnesite produced is insufficient compared to experiment.

These examples demonstrate the intricate kinetic behaviors of the magnesite, lizardite and $\mathrm{SiO}_{2}$ solid phases, due to the sharing of the $\mathrm{Mg}$ and $\mathrm{Si}$ released by the forsterite dissolution. Because lizardite occurs in both conservation laws, the amounts of the three precipitating phases are strongly coupled and constrained during the whole precipitation process. 


\section{CONCLUSION}

The present theoretical study analyzed the kinetic characteristics of precipitation of magnesite and lizardite as a result of hydrothermal alteration of olivine under high carbonate alkalinity at $200^{\circ} \mathrm{C}$. The simulations were performed with the help of the NANOKIN code which includes a full treatment of speciation processes in the aqueous solution, a rate equation for the dissolution of olivine, and a full account of nucleation and growth processes during the formation of secondary minerals.

The thermodynamic conditions of the alteration process were chosen similar to those of the experiments performed by Lafay et al. (2014). We have proposed a reinterpretation of the TGA data, allowing to determine the time evolution of the absolute amounts of each solid phase. We have found that, temporarily, the concentration of $\mathrm{Si}$ in the aqueous solution exceeds the solubility of amorphous silica, thus leaving the possibility that it precipitates.

We have succeeded in quantitatively reproducing both the experimental TGA results and the mean particle sizes observed with FESEM. The comparison between experimental and simulation results puts strong constraints on the simulation parameters, in particular those related to the nucleation and growth of the particles. It also brings additional information which complement the experimental results. It stresses that the in-situ $\mathrm{pH}$ value at $200^{\circ} \mathrm{C}$ is much lower $(\approx 7.3)$, albeit still alkaline, than in the state of the aqueous solution prepared at ambient temperature (ex-situ value equal to 8.7-8.9). It gives information on the silicon status during precipitation, pointing to an incongruent dissolution of olivine. It reveals a transitory precipitation of $\mathrm{SiO}_{2}$, not detected experimentally, showing that the fate of $\mathrm{Si}$ is more complex than a mere incorporation in lizardite. Moreover, thanks to the possibility of changing the input parameters, the simulation tool has highlighted how lizardite, magnesite and $\mathrm{SiO}_{2}$ compete for the incorporation of silicon and magnesium released by the olivine dissolution.

As a final remark, we would like to stress the interest of a complementary use of numerical modeling and experimental approaches in studies of fluid-rock interactions. As shown in the present work, modeling can help understanding what happens in aqueous solutions in terms of mineral saturations and subsequent kinetics of dissolution and precipitation. It also gives information of the time evolution of the particle populations of each mineral. Such a combined strategy may result crucial to address topics of societal importance, relevant in Earth systems like the functioning of hydrothermal fields, or in engineered systems like ex-situ and in-situ mineral sequestration of $\mathrm{CO}_{2}$.

\section{REFERENCES}

Adamson, A.W., 1960. Physical chemistry of surfaces. Interscience Publishers.

Andreani, M., Luquot, L., Gouze, P., Godard, M., Hoisé, E., Gibert, B., 2009. Experimental study of carbon sequestration reactions controlled by the percolation of $\mathrm{CO}_{2}$-rich brine through peridotites. Environ. Sci. Technol. 43, 1226-1231.

Bearat, H., Mckelvy, M.J., Chizmeshya, A.V.G., Gormley, D., Nunez, R., Carpenter, R.W., Squires, K., Wolf, G.H., 2006. Carbon sequestration via aqueous olivine mineral carbonation: role of passivating layer formation. Environ. Sci. Technol. 40, 4802-4808.

Blanc, Ph., Lassin, A., Piantone, P., Azaroual, M., Jacquemet, N., Fabbri, A., Gaucher, E.C., 2012. Thermoddem: A geochemical database focused on low temperature water/ rock interactions and waste materials. Appl. Geochem. 27 (10), 2107-2116.

Chen, Y., Brantley, S.L., 2000. Dissolution of forsteritic olivine at $65{ }^{\circ} \mathrm{C}$ and $2<\mathrm{pH}<5$. Chem. Geol. 165, 267-281.

Churakov, S.V., Iannuzzi, M., Parrinello, M., 2004. Ab Initio Study of Dehydroxylation-Carbonation Reaction on Brucite Surface. J. Phys. Chem. B 108, 11567-11574.

Daval, D., Sissmann, O., Menguy, N., Saldi, G.D., Guyot, F., Martinez, I., Corvisier, J., Garcia, B., Machouk, I., Knauss, K.G., Hellmann, R., 2011. Influence of amorphous silica layer formation on the dissolution rate of olivine at $90{ }^{\circ} \mathrm{C}$ and elevated $p_{\mathrm{CO}_{2}}$. Chem. Geol. 284, 193-209.

Fleming, S., Rohl, A., Lee, M-Y, Gale, J., Parkinson, G., 2000. Atomistic modelling of gibbsite: surface structure and morphology. J. Crystal Growth 209, 159-166.

Fournier, R.O., Potter, R.W., 1979. Magnesium correction to the Na-K-Ca chemical geothermometer. Geochem. Cosmochim. Acta 43, 1543-1555.

Fritz, B., 1981. Etude thermodynamique et modélisation des réactions hydrothermales et diagénétiques. Sci. Geol. Mém 65, 197p.

Fritz, B., Clément, A., Amal, Y., Noguera, C., 2009. Simulation of the nucleation and growth of simple clay minerals in weathering processes : the NANOKIN Code. Geochimica et Cosmochim. Acta. 73, 1340-1358.

Fritz, B., Clément, A., Montes-Hernandez, G., Noguera, C., 2013. Calcite formation by hydrothermal carbonation of portlandite: complementary insights from experiment and simulation. CrystEngComm. 15, 33923401.

Gadikota, G., Matter, J., Kelemen, P., Park, A.h.A., 2014. Chemical and morphological changes during olivine carbonation for $\mathrm{CO}_{2}$ storage in the presence of $\mathrm{NaCl}$ and $\mathrm{NaHCO}_{3}$. Phys. Chem. Chem. Phys. 16, 4679-4693.

Garcia, B., Beaumont, V., Perfetti, E., Rouchon, V., Blanchet, D., Oger, P., Dromart, G., Huc, A.-Y., Haeseler, F., 2010. Experiments and geochemical modeling 
of $\mathrm{CO}_{2}$ sequestration by olivine: potential, quantification. Appl. Geochem. 25, 1383-1396.

Giammar, D.E., Bruant Jr, R.G., Peters, C.A., 2005. Forsterite dissolution and magnesite precipitation at conditions relevant for deep saline aquifer storage and sequestration of carbon dioxide. Chem. Geol. 217, 257276.

Hänchen, M., Prigiobbe, V., Storti, G., Seward, T.M., Mazzotti, M., 2006. Dissolution kinetics of fosteritic olivine at $90-150^{\circ} \mathrm{C}$ including effects of the presence of $\mathrm{CO}_{2}$. Geochim. Cosmochim. Acta 70, 4403-4416.

Helgeson, H.C., Brown, T.H., Nigrini, A., Jones, T.A., 1970. Calculation of mass transfer in geochemical processes involving aqueous solutions. Geochim. Cosmochim. Acta 34, 569-592.

James, R.H., Allen, D.E., Seyfried Jr.,W.E., 2003. An experimental study of alteration of oceanic crust and terrigenous sediments at moderate temperatures (51 to $350^{\circ} \mathrm{C}$ ): insights as to chemical processes in nearshore ridge-flank hydrothermal systems. Geochim. Cosmochim. Acta 67, 681-691.

Jolivet, J.P., 2016. The aqueous chemistry of oxides. Oxford University Press, p26.

King, H.E., Plümper, O., Putnis, A., 2010. Effect of secondary phase formation on the carbonation of olivine. Environ. Sci. Technol. 44, 6503-6509.

Lafay, R., Montes-Hernandez, G., Janots, E., Chiriac, R., Findling, N., Toche, F., 2014. Simultaneous precipitation of magnesite and lizardite from hydrothermal alteration of olivine under high-carbonate alkalinity. Chemical Geology 368, 63-75.

Luce, R.W., Bartlett, R.W., Parks, G.A., 1972. Dissolution kinetics of magnesium silicates. Geochim. Cosmochim. Acta 36, 35-50.

Malvoisin, B., Brunet, F., Carlut, J., Rouméjon, S., Cannat, M., 2012. Serpentinization of oceanic peridotites: 2. Kinetics and processes of San Carlos olivine hydrothermal alteration. J. Geophys. Res. 117, 1-13.

Markov, I. V., 1995. Crystal growth for Beginners: fundamentals of nucleation, crystal growth and epitaxy. World Scientific (Singapore, New Jersey, London, Hong Kong), p98.

Michard, G., 1979, Geothermomètres chimiques. Bull. Bur. Rech. Géol. Min. Série. II, sect. III, 2, 183-189.

Montes-Hernandez, G., Renard, F., Chiriac, R., Findling, N., Toche, F., 2012a. Rapid precipitation of magnesite micro-crystals from $\mathrm{Mg}(\mathrm{OH})_{2}-\mathrm{H}_{2} \mathrm{O}-\mathrm{CO}_{2}$ slurry enhanced by $\mathrm{NaOH}$ and a heat-ageing step (from 20 to $90^{\circ} \mathrm{C}$ ). Cryst. Growth Des. 12, 5233-5240.

Montes-Hernandez, G., Chiriac, R., Toche, F., Renard, F., 2012b. Gas-solid carbonation of $\mathrm{Ca}(\mathrm{OH})_{2}$ and $\mathrm{CaO}$ particles under non-isothermal and isothermal conditions by using a thermo-gravimetric analyzer: implications for $\mathrm{CO}_{2}$ capture. Int. J. Greenhouse Gas Control 11, 172180.

Nielsen, A.E., Söhnel O., 1971. Interfacial tensions electrolyte crystal-aqueous solution, from nucleation data. J. Cryst. Growth 11, 233-242.
Noguera, C., Fritz, B., Clément, A., Baronnet, A., 2006a. Nucleation, growth and ageing in closed systems I : a unified model for precipitation in solution, condensation in vapor phase and crystallization in the melt. J. Crystal Growth 297, 180-186.

Noguera, C., Fritz, B., Clément, A., Baronnet, A., 2006b. Nucleation, growth and ageing in closed systems II : dynamics of formation of a new phase. J. Crystal Growth 297, 187-198.

Noguera, C., Fritz, B., Clément, A., Amal, Y., 2010. Simulation of the nucleation and growth of binary solid solutions in aqueous solutions. Chem Geol. 269, 89-99.

Noguera, C., Fritz, B., Clément, A., 2015. Precipitation mechanism of amorphous silica nanoparticles: A simulation approach. Journal of Colloid and Interface Science 448, 553-563.

Noguera C., Fritz B., Clément A., 2016. Kinetics of precipitation of non-ideal solid-solutions in a liquid environment. Chem. Geol. 431, 20-35.

Oelkers, E.H., 2001. An experimental study of forsterite dissolution rates as a function of temperature and aqueous $\mathrm{Mg}$ and Si concentrations. Chem. Geol. $175,485-494$.

Oelkers, E. H., Schott J., 2009. Thermodynamics and Kinetics of Water-Rock Interaction, Mineralogical Society of America and Geochemical Society, Rev. Mineral. Geochem., 70.

Palandri, J.L., Kharaka, Y.K., 2004. A compilation of rate parameters of water-mineral interaction kinetics for application to geochemical modeling. U.S. Geological Survey, open file report 2004-1068, 64p.

Parkhurst, D.L., Appello, C.A.J., 1999. User's guide to PHREEQC (Version 2). U.S. Department of the Interior, U.S.G.S.

Pokrovsky, O. S., Schott, J., 1999. Processes at the magnesium-bearing carbonates/solution interface. II. Kinetics and mechanism of magnesite dissolution. Geochim. Cosmochim. Acta 63, 881-897.

Prigiobbe, V. , Hänchen, M., Werner, M., Baciocchi, R., Mazzotti, M., 2009. Mineral carbonation process for $\mathrm{CO}_{2}$ sequestration. Energy Procedia 1, 4885-4890.

Rosso, J.J., Rimstidt, J.D., 2000. A high resolution study of forsterite dissolution rates. Geochim. Cosmochim. Acta 64, 797-811.

Schott, J., Pokrovsky, O.S., Oelkers, E.H., 2009. The Link Between Mineral Dissolution/Precipitation Kinetics and Solution Chemistry, in Thermodynamics and Kinetics of Water-Rock Interaction. Oelkers E. H. and Schott J., ed., Mineralogical Society of America and Geochemical Society, Rev. Mineral. Geochem. 70, chapter 6, p 207-258.

Söhnel O., 1982. Electrolyte crystal-aqueous solution interfacial tensions from crystallization data. J. Cryst. Growth 57, 101-108.

Sverdrup H., 1990. The Kinetics of Base Cation Release Due to Chemical Weathering. Lund University Press, Lund, Sweden.

http://webmineral.com/ 2014. Mineralogy Database. 